\title{
Prognostic nomogram for hepatocellular carcinoma with fibrosis of varying degrees
}

Rui Zhang

Zhongshan Hospital Fudan University

Jie Chen

Zhongshan Hospital Fudan University

Ying-yi Jiang

Zhongshan Hospital Fudan University

Jian Wang

Zhongshan Hospital Fudan University

Shi-yao Chen ( $\square$ csy10434@163.com )

Zhongshan Hospital Fudan University https://orcid.org/0000-0002-7276-1998

\section{Research article}

Keywords: Liver fibrosis, Hepatocellular carcinoma, Nomogram, Prognosis

Posted Date: November 20th, 2019

DOl: https://doi.org/10.21203/rs.2.17586/v1

License: (c) (i) This work is licensed under a Creative Commons Attribution 4.0 International License.

Read Full License 


\section{Abstract}

Background To investigate prognostic value of varying degrees of liver fibrosis in hepatocellular carcinoma (HCC) patients and establish an effective prognostic nomogram. Methods Eligible HCC patients with different degrees of fibrosis between 2004 and 2015 were matched from the Surveillance, Epidemiology, and End Results (SEER) database using propensity score matching (PSM). Prognostic value was evaluated using Kaplan-Meier and Cox hazard analysis. The nomogram on variables selected by multivariate analyses was established and subjected to internal validation. The predictive accuracy of nomograms was tested by concordance index (C-index) and calibration. Results HCC patients with advanced fibrosis/ cirrhosis was correlated with poor survival than those with none/moderate fibrosis in all patients [HR: $1.111,95 \% \mathrm{Cl}(1.042-1.185) ; \mathrm{p}=0.001]$ and in the PSM cohort [HR: $1.131,95 \% \mathrm{Cl}(1.032-$ 1.240); $p=0.009$ ]. Multivariate analysis of propensity-matched cohort revealed that age more than 63 , higher fibrosis score, AJCC stage T3-4, distant metastasis (M1), Tumor size $\geq 1$, vascular invasion and elevated AFP level were independent factors. The nomogram integrating these factors offers an effective prognostic prediction for $\mathrm{HCC}$ patients (C-index $0.749,95 \% \mathrm{Cl}: 0.735 \sim 0.763$ ) relative to AJCC 7th edition (0.727) and TNM (0.73). The calibration plots suggested optimal agreement between nomogram prediction and actual observation. Conclusions Increased fibrosis was an independent risk factor for HCC survival. The prognostic nomogram integrating fibrosis score offers a more accurate prediction.

\section{Background}

Hepatocellular carcinoma (HCC) ranks the fifth most common cancer, with up to $10 \%$ of cancer-related mortality worldwide and $70 \%-100 \%$ of cumulative risk of recurrence within 5 years after surgery [1-3]. The majority (70\%-90\%) of HCCs arises with advanced fibrosis and cirrhosis as a consequence of various etiologies [4]. Liver fibrosis is a protective wound healing response to chronic liver damage and becomes fibrous scar and cirrhosis when injury persists [5]. Often leading to hepatic dysfunction, fibrosis and cirrhosis was considered as a premalignant state that increased the HCC risk and development [6]. However, the effect of different fibrosis severities for liver fibrosis on HCC prognosis remains controversial.

Currently, there are two surgical staging systems, namely the Tumor-Node-Metastasis (TNM) from the Liver Cancer Study Group of Japan (LCSGJ) and the American Joint Committee on Cancer (AJCC) staging system. The $7^{\text {th }}$ edition of AJCC staging system adopting TNM classification is a commonly used staging systems and maintains the prognostic power for HCC patients [7]. Unfortunately, its application is not completely satisfactory for individual patients, especially for patients with advanced HCC [8]. One possible explanation for this imperfection lies in its failure to incorporate some other important characteristics such as age and sex in survival prediction. Nomogram is an effective and convenient statistical tool for prognostic prediction by combining all these factors and it has been developed in a variety of cancer types [9-11]. 
Through this SEER analysis, we aimed to evaluate the effect of different fibrosis degrees on HCC prognosis and to establish for the first time a prognostic nomogram integrating fibrosis score and other independent variables to predict HCC survival. Our model will provide precise prognostic information for clinicians in clinical practice.

\section{Methods}

\section{Patients selection and Data extraction}

We performed a retrospective cohort analysis by querying the SEER database (https://seer.cancer.gov/) for patients diagnosed with HCC [International Classification of Diseases for Oncology, Third Edition (ICD0-3), histology codes 8170-8175 for HCC and site code C22.0 for liver] between 2004 and 2015.

HCC patients younger than 18 years, those whose survival time and fibrosis score were unavailable, patients with the same ID number, patients diagnosed before 2004, patients with no evidence of primary cancer were excluded. Fibrosis score, also called Ishak score, was classified as F0-4 [code 0, fibrosis scores 0-4 (none to moderate fibrosis)] and F5-6 [code 1, fibrosis scores 5-6 (severe fibrosis or cirrhosis)]. We compared patients with none to moderate fibrosis (F0-4) to patients with severe fibrosis or cirrhosis (F5-6). AFP level was described using code10 (positive/elevated), code 20 (Negative/normal; within normal limits) and others. Considering in only sparse number of included patients whose tumor size were more than 3 or $5 \mathrm{~cm}$, we described tumor size as less than $1 \mathrm{~cm}$ (code 0-991), greater than $1 \mathrm{~cm}$ (code $992-$ 996) or other. We classified vascular invasion as absent, minor invasion (code200/350/370/380/400/520/550), major invasion (code 630/635/660) and other.

\section{Statistical analysis}

As previously described [12], 1:1 propensity score matching (PSM) analysis was carried out to minimize the selection bias and balance the baseline covariates between F0-4 and F5-6 group. After matching, covariate balance was tested and no covariates exhibiting a large imbalance indicated the adequacy of the constructed propensity score. Statistical analysis from SEER database was performed using SPSS 19.0 software. Continuous variables were presented as mean \pm standard deviation (SD) and was analyzed using unpaired $t$ test. Chi-square or Fisher's exact test was used to compare categorical variables. Survival curves were generated by Kaplan-Meier method (log-rank test). Significant factors affecting survival in univariable analysis were further determined by multivariable Cox regression analysis. The prognostic nomogram based on variables of multivariate analyses was established using the rms package in $\mathrm{R}$ project. The predictive accuracy and discriminative ability were determined by using concordance index (C-index) and calibration curve. A threshold of $\mathrm{P}<0.05$ was considered statistically significant.

\section{Results}


According to the eligibility criteria, a total of 8119 patients diagnosed with HCC between 2004 and 2015 were identified from the SEER database. Of these, 2295 patients were in F0-4 group and 5824 patients were in F5-6 group (Figure 1). Patients with advanced fibrosis and cirrhosis were more frequently

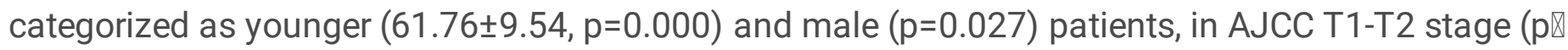
$0.0001)$, had no lymph node metastasis $(p=0.0065)$, had no distant metastasis $(p=0.0002)$, had positive AFP level ( $\mathrm{p} \otimes 0.0001)$. In contrast, patients with none/ moderate fibrosis were more frequently classified as older and female patients, in AJCC stage T3-T4, with negative AFP level. Since the comparison of different degrees of liver fibrosis is subject to possible confounding induced by differences in baseline characteristics, we performed PSM to generate 1:1 pairs of patients. The matched groups consisted of 1660 F0-4 and 1563 F5-6 patients diagnosed with HCC (Figure 1). The covariates between the two groups were well-balanced and showed no significant differences at baseline ( $\mathrm{p} \otimes 0.05$ for all; Table 1 and figure $2 A, 2 B)$.

\section{Increased fibrosis progression correlated with poor prognosis of HCC patients}

In entire cohort of patients, the overall survival (OS) rate was significantly higher in patients of F0-4 group than those in F5-6 group (1-, 3-, 5-year cumulative OS rates were $65.8 \%, 44.5 \%$ and $33.9 \%$ vs $62.3 \%, 41.2 \%$ and $32.0 \%$, respectively). Patients with advanced fibrosis/cirrhosis showed unfavorable prognosis $(p=0.029)$ (figure $2 C)$. The median overall survival (OS) time was longer in patients of F0-4 group than that of F5-6 group (27 versus 23 months) (Table 2). After one-to-one PSM, the 1-, 3-, 5-year cumulative OS rates were $70.6 \%, 49.6$ and $37.6 \%$ in F0-4 group and $65.8 \%, 47.7 \%$ and $34.7 \%$ in F5-6 group, respectively. The median OS time was again longer in patients of F0-4 group than that of F5-6 group (36 versus 28 months). Patients with advanced fibrosis/cirrhosis also showed unfavorable prognosis $(p=0.028)$ (figure 2D). In univariate analysis of all matched patients, age $(p=0.000)$, sex $(p=0.008)$, primary tumor $(p=0.000)$, lymph node metastasis $(p=0.000)$, distant metastasis $(p=0.000)$, vascular invasion $(p=0.000)$, AFP level $(p=0.000)$, fibrosis score $(p=0.028)$ and tumor size $(p=0.000)$ were closely associated with OS (Table 2). The multivariate Cox proportional hazards analysis for those factors showing significance by univariate analysis showed that advanced fibrosis/ cirrhosis (HR:1.131, 95\% Cl: 1.032-1.240, $p=0.009$ ), age more than 63 (HR: 1.365, $p=0.000)$, AJCC stage T3-4 (HR: 1.810, $p=0.000)$, distant metastasis (M1) (HR: 3.460, $p=0.000)$, tumor size $\geq 1 \mathrm{~cm}$ (HR: 2.536, $p=0.000)$, minor vascular invasion (HR: 1.202, $p=0.05$ ), major vascular invasion (HR: 2.321, $p=0.000$ ) as well as elevated AFP level (HR: $1.511, p=0.000)$ were independent risk factors for increased mortality rate (Table 3 ).

\section{Predictors of survival among advanced fibrosis/cirrhosis patients}

Using multivariate analysis, predictors of survival among advanced fibrosis/cirrhosis patients were performed. As shown in Table 4, advanced fibrosis/cirrhosis patients whose age older than 63-year old demonstrated worse survival (HR: 1.480, 95\%Cl: 1.297-1.689, $\mathrm{p}=0.000)$ ). In advanced fibrosis/cirrhosis patients, AJCC stage T3-4 (HR: 1.900, 95\%Cl: 1.477 2.444, p=0.000), distant metastasis (M1) (HR: 3.270 , 95\%Cl: 2.297-4.655, $p=0.000)$, Tumor size $\geq 1 \mathrm{~cm}$ (HR: 2.809, 95\%Cl: $2.152 \sim 3.668, p=0.000)$ and major vascular invasion (HR: 2.457, 95\% Cl: 1.819-3.319, $p=0.000$ ) were associated with worse survival. Negative 
AFP HCC patients demonstrated better survival than positive patients (HR: 0.702, 95\%Cl: 0.594 0.831, $p=0.000)$.

\section{Prognostic Nomogram construction and validation}

The prognostic nomogram integrated all significant independent factors for survival in multivariate analyses (Figure 3A). The C-index for survival prediction was 0.749 (95\% Cl: $0.735 \sim 0.763$ ). In addition, the calibration plot for the probability of survival at 1, 3 and 5 year presented an optimal agreement between the prediction by nomogram and actual observation (Figure 3B). Thirty percent of all cohort was randomly generated by $\mathrm{R}$ software to make internal validation. The $\mathrm{C}$-index of internal validation of the nomogram was $0.761(95 \% \mathrm{Cl} 0.736 \sim 0.786)$, calibration curves also showed good agreement between prediction and observation in 1-, 3- and 5-year OS (Figure 3C). These results indicated the nomogram that integrated fibrosis score with other factors of age, AJCC T stage, distant metastasis, tumor size, vascular invasion and AFP level was reliable for survival prediction of HCC patients.

\section{Comparison between nomogram and single independent factors/ conventional staging systems}

The larger of the $\mathrm{C}$-index represented a more accurate the predictive model. The $\mathrm{C}$-index of the prognostic nomogram was larger than the AJCC $7^{\text {th }}$ edition, the AJCC TNM staging system, and single independent factors. For the nomogram of primary cohort, the C-index for survival prediction was 0.749 ( $95 \% \mathrm{Cl}$ : 0.735 0.763), which was higher than AJCC $7^{\text {th }}$ edition (C-index 0.727), AJCC TNM stage (C-index 0.73), tumor size (C-index 0.506), vascular invasion (C-index 0.509), AFP (C-index 0.55), and age (C-index 0.536) (p囚0.05). For internal validation of the nomogram, the C-index was $0.761(95 \% \mathrm{Cl} 0.736 \sim 0.786)$, which was also higher than AJCC $7^{\text {th }}$ edition (C-index 0.732), AJCC TNM stage (C-index 0.742), tumor size (Cindex 0.502), vascular invasion (C-index 0.520), AFP (C-index 0.539), and age (C-index 0.534) (p囚0.05). Taken together, these results suggest that the nomogram was useful and reliable predicting model for survival of patients with HCC relative to the AJCC $7^{\text {th }}$ edition and AJCC TNM stage system.

\section{Discussion}

In this study, we demonstrated that advanced fibrosis/ cirrhosis was independently associated with HCC survival and for the first time established and internally validated a fibrosis score-based nomogram for HCC survival prediction. This prognostic model integrating fibrosis score was reliable, robust and practical for HCC patients.

HCC is closely associated with liver fibrosis and its end-stage, cirrhosis, with about $80-90 \%$ of HCC patients having underlying fibrosis and approximately one in three cases with liver cirrhosis will develop $\mathrm{HCC}$ in their lifetime. The incidence rate of HCC within 5 years in patients with advanced liver fibrosis/ cirrhosis ranges from $5 \%$ to $30 \%[6,13]$. However, the impact of fibrosis score on survival outcome in HCC has yet been reached [14-17]. Therefore, a better understanding of the role of fibrosis score in HCC prognosis and a nomogram constructed to include fibrosis score may provide more-accurate prognostic prediction for HCC patients. 
Fibrosis score is also called Ishak score. AJCC classifies fibrosis scores as none to moderate fibrosis and severe fibrosis or cirrhosis. To eliminate selection bias, we categorized the entire study population into groups with different degrees of fibrosis (none/ moderate fibrosis and advanced fibrosis/ cirrhosis) using the propensity score analyses. No significant difference in factors of age, sex, AJCC TNM stage, AFP level, tumor size and vascular invasion indicated the patients of both groups was well-balanced. Previously, Noda et al found no significantly association between liver fibrosis and OS of HCC patients $(p=0.1185)[18]$. Also, Suh et al found no significant difference in OS between mild and severe fibrosis ( $P$ $=0.267$ ) [14]. However, our results revealed that advanced fibrosis/ cirrhosis provided worse survival than none/ moderate fibrosis. In addition, severe fibrosis/ cirrhosis was an independent risk factor for OS. This finding was consistent with a recent meta-analysis by Zhang et al and the study by Toyoda et al [19, 20]. The discrepancies may be partly attributed to the different criteria of enrolling patients. Noda et al evaluated the effect of different degrees of fibrosis on the prognosis of non-viral HCC patients [18]. Suh et al investigated the influence of liver fibrosis on prognosis only for $\mathrm{HCC}$ with Child-Pugh grade $\mathrm{A}$ and a single $\mathrm{HCC}<5 \mathrm{~cm}$ [14]. Appropriately $70 \% \mathrm{HCC}$ patients were afflicted with hepatitis virus infection [6]. Child-Pugh class B and HCV positivity were also associated with the poor prognosis of HCC [21]. Our study synthetically explored the relationship between fibrosis score and clinical prognosis of HCC.

In the multivariate analyses, besides fibrosis score, age more than 63, AJCC stage T3-4, distant metastasis (M1), tumor size $\geq 1 \mathrm{~cm}$, minor and major vascular invasion, and elevated AFP level were identified as independent predictors for poor prognosis of HCC, which was in agreements with previous studies [8, 22-25]. Consistency with previous studies [25, 26], sex and lymph node metastasis failed to stratify survival in our study. In addition, we used multivariate analysis to identify predictors of survival among advanced fibrosis/cirrhosis patients and the results showed that advanced fibrosis/cirrhosis patients whose age older than 63-year old demonstrated worse survival. In advanced fibrosis/cirrhosis patients, AJCC stage T3-4, distant metastasis (M1), Tumor size $\geq 1 \mathrm{~cm}$, major vascular invasion and positive AFP level were associated with worse survival. Subsequently, we developed a nomogram that incorporated the predictors to predict the patients' survival. The C-index of our nomogram and internally validated nomogram was 0.749 and 0.761 , which was higher than AJCC $7^{\text {th }}$ edition (entire cohort: 0.727 , validation cohort: 0.732 ) and AJCC TNM staging system (entire cohort: 0.730 , validation cohort: 0.742 ). The calibration plot for the 1-, 3-, or 5-year probability of survival showed an optimal agreement between the prediction by the nomogram and actual observation in both the entire cohort and validation cohort.

Our study has several limitations that may affect the results to some extent. Firstly, the nomogram was constructed based on data from the SEER databases, which lacked the record of HCC etiology (e.g. viral status), liver function index, Child-Pugh class or severity of portal hypertension and performance status. Therefore, the predictive accuracy of our nomogram failed to be compared with Barcelona Clinic Liver Cancer (BCLC) scoring system [27]. Secondly, large amount of data was unclear. This represented a strong limitation to conclusion on survival and the established nomogram. Thirdly, it is well-known that HBV suppression with nucleos(t)ide analogues and HCV eradication with direct-acting antivirals (DAAs) or with pegylated interferon have a significant impact on hepatic decompensation and ultimately on survival of patients with HCC. For the same reasons, another critical point is the lack of data on HCC 
treatment received by patients, that could significantly affect survival. Fourthly, although PSM was applied to minimize the potential bias, the retrospective nature of this study made it hard to avoid other biases caused by some confounding factors. A further validation from prospective or randomized control trials were required. Finally, this analysis was performed based on a database and validated internally. Therefore, externally validations with more patients from other institutions or study groups were warranted.

\section{Conclusions}

Our study proposed that HCC patients with advanced fibrosis/cirrhosis had a poor outcome than those with lower degrees of fibrosis. We established a reliable and superior nomogram based on fibrosis score and other independent risk factors to predict the prognosis of patients with HCC.

\section{Declarations}

\section{Ethics approval and consent to participate}

Not applicable.

\section{Consent for publication}

Not applicable.

\section{Abbreviations}

HCC, Hepatocellular carcinoma; AJCC, American Joint Committee on Cancer; DCA, decision curve analysis; OS, overall survival; TNM, Tumor-Node-Metastasis; LCSGJ, the Liver Cancer Study Group of Japan; C-index, concordance index; BCLC, Barcelona Clinic Liver Cancer.

\section{Author's contributions}

SYC conceived and designed the study. RZ, JC, YYJ and JW performed the statistical analysis. RZ and SYC analyzed the data and wrote the manuscript. All authors read and approved the final manuscript.

\section{Acknowledgements}

Not applicable.

\section{Funding}

This work was supported by the Innovation Fund of Science and Technology Commission of Shanghai Municipality (No. 15411950501, 15411950507 and 17140902700).

\section{Competing interests}


The authors declared no conflict of interests.

\section{Availability of data and materials}

The datasets generated during the current study are publicly archived from SEER database (https://seer.cancer.gov/) and are available from the corresponding author on reasonable request.

\section{References}

1. Marrero JA, Kulik LM, Sirlin CB, Zhu AX, Finn RS, Abecassis MM, et al. Diagnosis, Staging, and Management of Hepatocellular Carcinoma: 2018 Practice Guidance by the American Association for the Study of Liver Diseases. Hepatology 2018;68(2):723-750.

2. Rahbari NN, Mehrabi A, Mollberg NM, Müller SA, Koch M, Büchler MW, et al. Hepatocellular carcinoma: current management and perspectives for the future. Ann Surg 2011;253(3):453-469.

3. Poon RT, Fan ST, Lo CM, Liu CL, Wong J. Long-term survival and pattern of recurrence after resection of small hepatocellular carcinoma in patients with preserved liver function: implications for a strategy of salvage transplantation. Ann Surg 2002;235(3):373-382.

4. El-Serag HB, Rudolph KL. Hepatocellular carcinoma: epidemiology and molecular carcinogenesis. Gastroenterology 2007;132:2557-2576.

5. Hernandez-Gea V, Friedman SL. Pathogenesis of liver fibrosis. Annu Rev Pathol 2011; 6:425-456.

6. Fattovich G, Stroffolini T, Zagni I, Donato F. Hepatocellular carcinoma in cirrhosis: incidence and risk factors. Gastroenterology 2004; 127 Suppl 1:35-50.

7. Edge SB, Carducci MA, Compton CC, et al. AJCC cancer staging manual. 7th ed. Chicago: Springer; 2009. p. 237.

8. Chun YH, Kim SU, Park JY, Kim DY, Han KH, Chon CY, et al. Prognostic value of the 7th edition of the AJCC staging system as a clinical staging system in patients with hepatocellular carcinoma. Eur $\mathrm{J}$ Cancer 2011;47(17):2568-2575.

9. Balachandran VP, Gonen M, Smith JJ, DeMatteo RP. Nomograms in oncology: more than meets the eye. Lancet Oncol 2015;16(4):e173-180.

10. Karakiewicz PI, Briganti A, Chun FK, Trinh QD, Perrotte P, Ficarra V, et al. Multi-institutional validation of a new renal cancer- specific survival nomogram. J Clin Oncol 2007; 25(11):1316-1322.

11. Wang Y, Li J, Xia Y, Gong R, Wang K, Yan Z, et al. Prognostic nomogram for intrahepatic cholangiocarcinoma after partial hepatectomy. J Clin Oncol 2013;31(9):1188-1195.

12. Pattanayak CW, Rubin DB, Zell ER. Propensity score methods for creating covariate balance in observational studies. Rev Esp Cardiol 2011;64(10):897-

13. El-Serag HB. Hepatocellular carcinoma. N Engl J Med 2011;365:1118-27.

14. Suh SW, Choi YS. Influence of liver fibrosis on prognosis after surgical resection for resectable single hepatocellular carcinoma. ANZ J Surg 2019;89(3):211-215. 
15. Huang JL, Fu YP, Jing CY, Yi Y, Sun J, Gan W, et al. A novel and validated prognostic nomogram based on liver fibrosis and tumor burden for patients with hepatocellular carcinoma after curative resection. J Surg Oncol 2018;117(4):625-633.

16. Taura K, Ikai I, Hatano E, Yasuchika K, Nakajima A, Tada M, et al. Influence of coexisting cirrhosis on outcomes after partial hepatic resection for hepatocellular carcinoma fulfilling the Milan criteria: an analysis of 293 patients. Surgery 2007;142(5):685-694.

17. Sasaki K, Shindoh J, Margonis GA, Nishioka Y, Andreatos N, Sekine A, et al. Effect of Background Liver Cirrhosis on Outcomes of Hepatectomy for Hepatocellular Carcinoma. JAMA Surg 2017;152(3):e165059.

18. Noda Y, Kawaguchi T, Korenaga M, Yoshio S, Komukai S, Nakano M, et al. High Serum Interleukin-34 Level is a Predictor of Poor Prognosis in Patients with Non-viral Hepatocellular Carcinoma. Hepatol Res 2019.

19. Zhang Y, Wang R, Yang X. FIB-4 index serves as a noninvasive prognostic biomarker in patients with hepatocellular carcinoma: A meta-analysis. Medicine (Baltimore) 2018;97(51):e13696.

20. Toyoda H, Kumada T, Tada T, Yama T, Mizuno K, Sone Y, et al. Differences in the impact of prognostic factors for hepatocellular carcinoma over time. Cancer Sci 2017;108(12):2438-2444.

21. Chen RX, Gan YH, Ge NL, Chen Y, Ma H, Wang Y, et al. Comparison of transarterial chemoembolization with radiofrequency ablation for unresectable Barcelona Clinic Liver Cancer stage 0/A hepatocellular carcinoma: a propensity score matching. J Gastroenterol Hepatol 2016;31(2):442-449.

22. Zhang W, Liu C, Tan Y, Jiang L, Yan L, Yang J, et al. Role of liver resection in treating intermediate and advanced stage adolescent and young adult hepatocellular carcinoma patients: A propensitymatching cohort study. Int J Surg 2018;54:259-264.

23. Borzio M, Dionigi E, Rossini A, Marignani M, Sacco R, De Sio I, et al. External validation of the ITA.LI.CA prognostic system for patients with hepatocellular carcinoma: A multicenter cohort study. Hepatology 2018;67(6):2215-2225.

24. Fung J, Cheung KS, Wong DK, Mak LY, To WP, Seto WK, et al. Long-term outcomes and predictive scores for hepatocellular carcinoma and hepatitis B surface antigen seroclearance after hepatitis B eantigen seroclearance. Hepatology 2018;68(2):462-472.

25. Lin Q, Huang X, Zhong C, Luo T, Zeng X, Chen S. Improved survival with radiotherapy in hepatocellular carcinoma with major vascular invasion: A propensity-matched analysis of Surveillance, Epidemiology, and End Results database. Cancer Med 2019;8(2):515-526.

26. Harimoto N, Yoshizumi T, Inokuchi S, Itoh S, Adachi E, Ikeda Y, et al. Prognostic Significance of Preoperative Controlling Nutritional Status (CONUT) Score in Patients Undergoing Hepatic Resection for Hepatocellular Carcinoma: A Multi-institutional Study. Ann Surg Oncol 2018;25(11):3316-3323.

27. Forner A, Reig ME, de Lope CR, Bruix J. Current strategy for staging and treatment: the BCLC update and future prospects. Semin Liver Dis 2010;30:61-74. 


\section{Tables}

Table 1 The baseline characteristics of HCC patients with different fibrosis scores after PSM.

\begin{tabular}{|c|c|c|c|c|c|c|}
\hline \multirow[t]{2}{*}{ iable } & \multicolumn{3}{|c|}{ Before PSM } & \multicolumn{3}{|c|}{ After PSM } \\
\hline & $\begin{array}{l}\text { F0-4 } \\
(\mathrm{n}=2295)\end{array}$ & $\begin{array}{l}\text { F5-6 } \\
(\mathrm{n}=5824)\end{array}$ & $P$ value & $\begin{array}{l}\text { F0-4 } \\
(n=1660)\end{array}$ & $\begin{array}{l}\text { F5-6 } \\
(\mathrm{n}=1563)\end{array}$ & $\begin{array}{l}\mathrm{P} \\
\text { value }\end{array}$ \\
\hline $\begin{array}{l}\text { an age (SD) } \\
\therefore, \mathrm{n}\end{array}$ & $63.84 \pm 12.13$ & $61.76 \pm 9.54$ & 0.000 & $63.54 \pm 9.62$ & $63.43 \pm 9.24$ & 0.248 \\
\hline le & 1742 & 4555 & 0.027 & 1320 & 1254 & 0.614 \\
\hline nale & 553 & 1269 & & 340 & 309 & \\
\hline \multicolumn{7}{|l|}{ C T, 7th ed, n } \\
\hline $\mathrm{T} 2$ & 922 & 2707 & \multirow{3}{*}{$\begin{array}{l}< \\
0.0001\end{array}$} & 729 & 705 & \multirow[t]{3}{*}{0.755} \\
\hline T4 & 361 & 762 & & 201 & 180 & \\
\hline known & 1012 & 2355 & & 730 & 678 & \\
\hline \multicolumn{7}{|l|}{ :C N, 7th ed, n } \\
\hline & 1211 & 3283 & \multirow[t]{3}{*}{0.0065} & 909 & 869 & \multirow[t]{3}{*}{0.721} \\
\hline & 72 & 197 & & 19 & 14 & \\
\hline known & 1012 & 2344 & & 732 & 680 & \\
\hline \multicolumn{7}{|l|}{ :C M, 7th ed, n } \\
\hline & 1175 & 3250 & \multirow[t]{3}{*}{0.0002} & 890 & 844 & \multirow[t]{3}{*}{0.950} \\
\hline & 143 & 387 & & 47 & 46 & \\
\hline snown & 977 & 2187 & & 723 & 673 & \\
\hline \multicolumn{7}{|l|}{$?, \mathrm{n}$} \\
\hline ;itive/elevated & 1217 & 3531 & \multirow{4}{*}{$\begin{array}{l}< \\
0.0001\end{array}$} & 958 & 911 & \multirow[t]{3}{*}{0.749} \\
\hline yative & 648 & 1411 & & 432 & 413 & \\
\hline zlear & 430 & 882 & & 270 & 239 & \\
\hline \multicolumn{6}{|l|}{ nor size, $\mathrm{n}$} & \\
\hline $\mathrm{m}$ & 2091 & 5262 & \multirow[t]{3}{*}{0.3470} & 1583 & 1492 & \multirow[t]{2}{*}{0.896} \\
\hline m & $\begin{array}{l}7 \\
197\end{array}$ & $\begin{array}{l}12 \\
550\end{array}$ & & $\begin{array}{l}0 \\
77\end{array}$ & $\begin{array}{l}0 \\
71\end{array}$ & \\
\hline \multicolumn{6}{|l|}{;cular invasion, n } & \\
\hline ient & 920 & 2219 & \multirow{4}{*}{$\begin{array}{l}< \\
0.0001\end{array}$} & 761 & 713 & \multirow[t]{4}{*}{0.909} \\
\hline lor invasion & 284 & 399 & & 138 & 120 & \\
\hline $\begin{array}{l}\text { jor invasion (code } \\
1 / 635 / 660 \text { ) }\end{array}$ & 185 & 475 & & 91 & 87 & \\
\hline known & 906 & 2731 & & 670 & 643 & \\
\hline
\end{tabular}

AFP, Alpha Fetoprotein; AJCC, American Joint Committee on Cancer; PSM, propensity score matching.

Table 2 Univariate analysis of prognostic factors associated with overall survival (OS) after propensity score matching 


\begin{tabular}{|c|c|c|c|c|c|c|}
\hline \multirow[t]{2}{*}{ Variable } & \multicolumn{3}{|c|}{ Before PSM } & \multicolumn{3}{|c|}{ After PSM } \\
\hline & $\begin{array}{l}\text { All } \\
\text { patients }\end{array}$ & $\begin{array}{l}\text { Survival time (months) } \\
\text { median }(95 \% \mathrm{CI})\end{array}$ & $\begin{array}{l}\mathrm{P} \\
\text { value } \\
\end{array}$ & $\begin{array}{l}\text { All } \\
\text { patients }\end{array}$ & $\begin{array}{l}\text { Survival time (months) } \\
\text { median }(95 \% \mathrm{CI})\end{array}$ & $\begin{array}{l}\mathrm{P} \\
\text { value } \\
\end{array}$ \\
\hline $\begin{array}{l}\text { Group, } \mathrm{n} \\
\text { F0-4 }\end{array}$ & 2295 & 27(23.999-30.001) & 0.029 & 1660 & 36(32.191-39.809) & 0.028 \\
\hline F5-6 & 5824 & $23(21.465-24.535)$ & & 1563 & $28(24.265-31.735)$ & \\
\hline \multicolumn{7}{|l|}{ Age, $\mathrm{n}$} \\
\hline$\leq 63$ & 4695 & $30(27.516-32.484)$ & 0.000 & 1692 & $40(35.293-44.707)$ & 0.000 \\
\hline$\square 63$ & 3424 & $20(18.51-21.49)$ & & 1531 & $25(22.395-27.605)$ & \\
\hline \multicolumn{7}{|l|}{ Sex, $n$} \\
\hline Male & 6297 & $24(22.491-25.509)$ & 0.025 & 2574 & $30(26.955-33.045)$ & 0.008 \\
\hline Female & 1822 & $27(23.862-30.138)$ & & 649 & 37(29.635-44.365) & \\
\hline \multicolumn{7}{|l|}{ AJCC T, 7th ed, n } \\
\hline T1-T2 & 3629 & 44(39.689-48.311) & 0.000 & 1434 & 56 & 0.000 \\
\hline T3-T4 & 1123 & 7(6.046-7.954) & & 381 & $9(7.077-10.923)$ & \\
\hline Unclear & 3367 & $19(17.365-20.635)$ & & 1408 & $22(19.305-24.695)$ & \\
\hline \multicolumn{7}{|l|}{ AJCC N, 7th ed, n } \\
\hline No & 4494 & $32(29.665-34.335)$ & 0.000 & 1778 & $42(37.736-46.264)$ & 0.000 \\
\hline N1 & 269 & 4(3.095-4.905) & & 33 & $4(1.908-6.092)$ & \\
\hline Unclear & 3356 & $20(18.367-21.633)$ & & 1412 & $22(19.307-24.693)$ & \\
\hline \multicolumn{7}{|l|}{ AJCC M, 7th ed, n } \\
\hline M0 & 4425 & $33(30.567-35.433)$ & 0.000 & 1734 & $42(37.38-46.62)$ & 0.000 \\
\hline M1 & 530 & $3(2.494-3.506)$ & & 93 & $4(3.191-4.809)$ & \\
\hline Unclear & 3164 & $21(19.190-22.81)$ & & 1396 & $23(20.243-25.757)$ & \\
\hline \multicolumn{7}{|c|}{ Vascular invasion, n } \\
\hline Absent & 3139 & $52(47.312-56.688)$ & 0.000 & 1474 & $59(49.969-68.031)$ & 0.000 \\
\hline Minor & 683 & $30(25.482-34.518)$ & & 258 & $36(24.221-47.779)$ & \\
\hline Major & 660 & $4(3.281-4.719)$ & & 178 & 7(4.961-9.039) & \\
\hline Unclear & 3637 & 17(15.722-18.278) & & 1313 & 17(14.85-19.15) & \\
\hline \multicolumn{7}{|l|}{$\mathrm{AFP}, \mathrm{n}$} \\
\hline Positive/elevated & 4748 & 19(17.785-20.215) & 0.000 & 1869 & $23(20.536-25.464)$ & 0.000 \\
\hline $\begin{array}{l}\text { Negative } \\
\text { Unclear }\end{array}$ & $\begin{array}{l}2059 \\
1312\end{array}$ & $\begin{array}{l}47(41.161-52.839) \\
21(17.714-24.286)\end{array}$ & & $\begin{array}{l}845 \\
509\end{array}$ & $\begin{array}{l}57(48.156-65.844) \\
25(19.72-30.28)\end{array}$ & \\
\hline \multicolumn{7}{|l|}{ Tumor size, $\mathrm{n}$} \\
\hline$\leq 1 \mathrm{~cm}$ & 7353 & $30(28.238-31.762)$ & 0.000 & 3075 & 35(32.288-37.712) & 0.000 \\
\hline$\square 1 \mathrm{~cm}$ & 19 & $13(0-27.348)$ & & 0 & - & \\
\hline Unclear & 747 & $2(1.568-2.432)$ & & 148 & $2(1.069-2.931)$ & \\
\hline
\end{tabular}

AFP, Alpha Fetoprotein; AJCC, American Joint Committee on Cancer; OS, overall survival; PSM, propensity score matching. 
Table 3 Multivariate analysis of factors predictive of patients' overall survival after propensity score matching.

\begin{tabular}{|c|c|c|c|c|}
\hline \multirow[t]{2}{*}{ Variable } & \multicolumn{2}{|l|}{ Before PSM } & \multicolumn{2}{|l|}{ After PSM } \\
\hline & HR (95\%CI) & $\begin{array}{c}\mathrm{p} \\
\text { Value }\end{array}$ & HR (95\%CI) & $\begin{array}{c}\mathrm{p} \\
\text { Value }\end{array}$ \\
\hline Group F5-6 (versus F0-4) & $1.111(1.042-1.185)$ & 0.001 & $1.131(1.032-1.240)$ & 0.009 \\
\hline Age $₫ 63 \rrbracket$ versus $\leq 63 \square$ & $1.447(1.366-1.533)$ & 0.000 & $1.365(1.243-1.498)$ & 0.000 \\
\hline Sex Female (versus male) & $0.917(0.856-0.983)$ & 0.014 & & \\
\hline AJCC T, 7th ed, n (\%) & 1.683(1.517 1.867) & 0.000 & $1.810(1.517 \sim 2.159)$ & 0.000 \\
\hline \multicolumn{5}{|l|}{ T3-4 (versus T1-2) } \\
\hline AJCC N, 7th ed, n (\%) & $1.364(1.168-1.594)$ & 0.000 & & \\
\hline \multicolumn{5}{|l|}{ N1 (versus N0) } \\
\hline AJCC M, 7th ed & $2.328(2.068-2.621)$ & 0.000 & $3.460(2.705-4.424)$ & 0.000 \\
\hline \multicolumn{5}{|l|}{ M1(versus M0) } \\
\hline $\begin{array}{l}\text { Tumor size } \geq 1 \mathrm{~cm} \\
\text { (versus } \square 1 \mathrm{~cm} \text { ) }\end{array}$ & $1.417(0.837 \sim 2.399)$ & 0.194 & $2.536(2.096 \sim 3.068)$ & 0.000 \\
\hline Vascular invasion Minor & $1.267(1.132-1.418)$ & 0.000 & $1.202(1.000-1.445)$ & 0.050 \\
\hline (versus none) & & & & \\
\hline Vascular invasion Major & $2.401(2.134-2.701)$ & 0.000 & $2.321(1.885-2.857)$ & 0.000 \\
\hline (versus none) & & & & \\
\hline $\begin{array}{l}\text { AFP Negative (versus } \\
\text { Positive/elevated) }\end{array}$ & $0.670(0.622 \sim 0.721)$ & 0.000 & $0.662(0.587-0.746)$ & 0.000 \\
\hline
\end{tabular}

AFP, Alpha Fetoprotein; AJCC, American Joint Committee on Cancer; HR, hazard ratio; CI, confidence interval; PSM, propensity score matching.

Table 4 Multivariate analysis of factors predictive of patients' overall survival in advanced fibrosis/ cirrhosis HCC group. 


\begin{tabular}{lcc}
\hline Variable & HR (95\%CI) & p Value \\
\hline Age $\square 63 \square$ versus $\leq 63 \square$ & $1.480(1.297-1.689)$ & 0.000 \\
Derived AJCC T, 7th ed, n (\%) & $1.900(1.477 \sim 2.444)$ & 0.000 \\
T3-4 (versus T1-2) & & \\
Derived AJCC M, 7th ed & $3.270(2.297-4.655)$ & 0.000 \\
M1(versus M0) & & \\
Tumor size $\geq 1 \mathrm{~cm}$ & $2.809(2.152 \sim 3.668)$ & 0.000 \\
(versus $\square 1 \mathrm{~cm})$ & & \\
& & 0.181 \\
Vascular invasion Minor & $1.200(0.918-1.569)$ & \\
(versus none) & & 0.000 \\
Vascular invasion Major & $2.457(1.819-3.319)$ & \\
(versus none) & & 0.000 \\
AFP Negative (versus Positive/elevated) & $0.702(0.594 \sim 0.831)$ & \\
& & \\
\hline
\end{tabular}

AFP, Alpha Fetoprotein; AJCC, American Joint Committee on Cancer; HR, hazard ratio; CI, confidence interval.

\section{Figures}

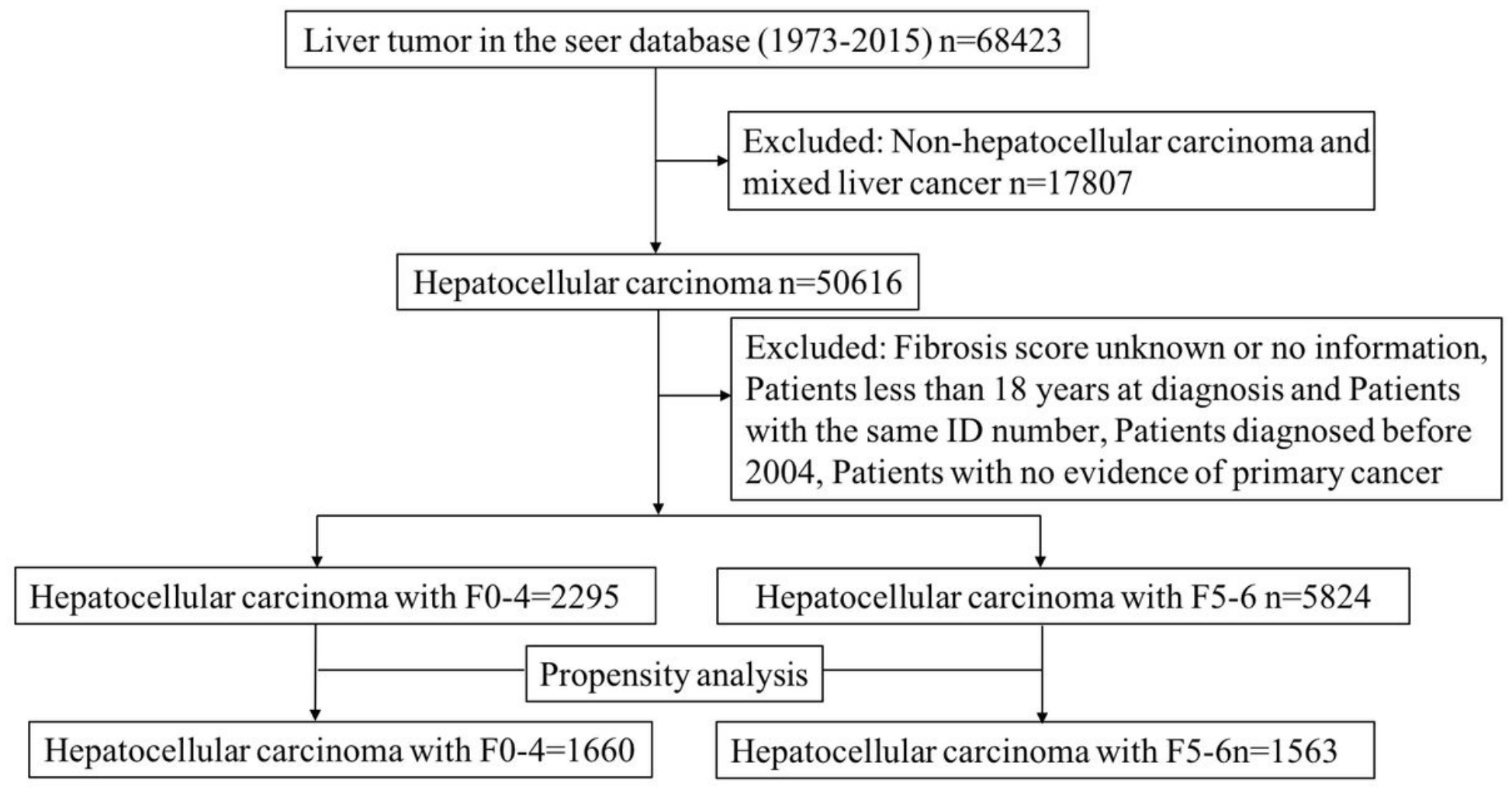

Figure 1 


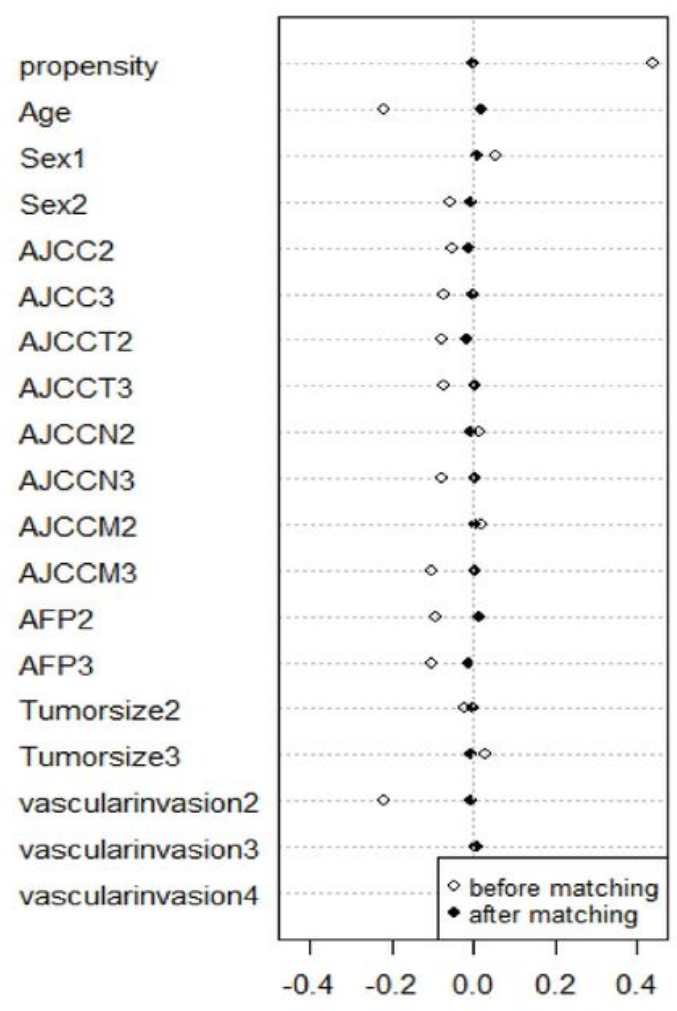

C

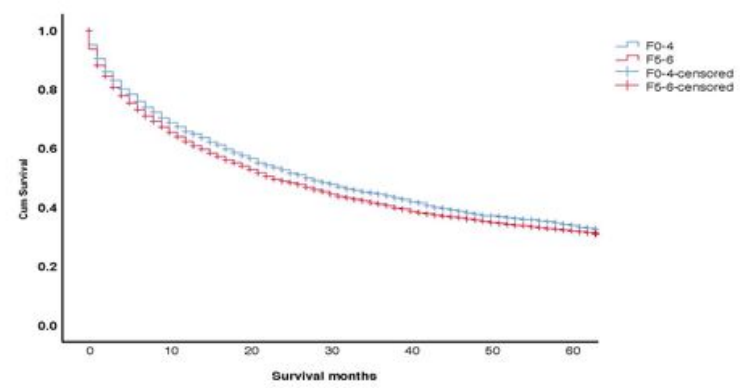

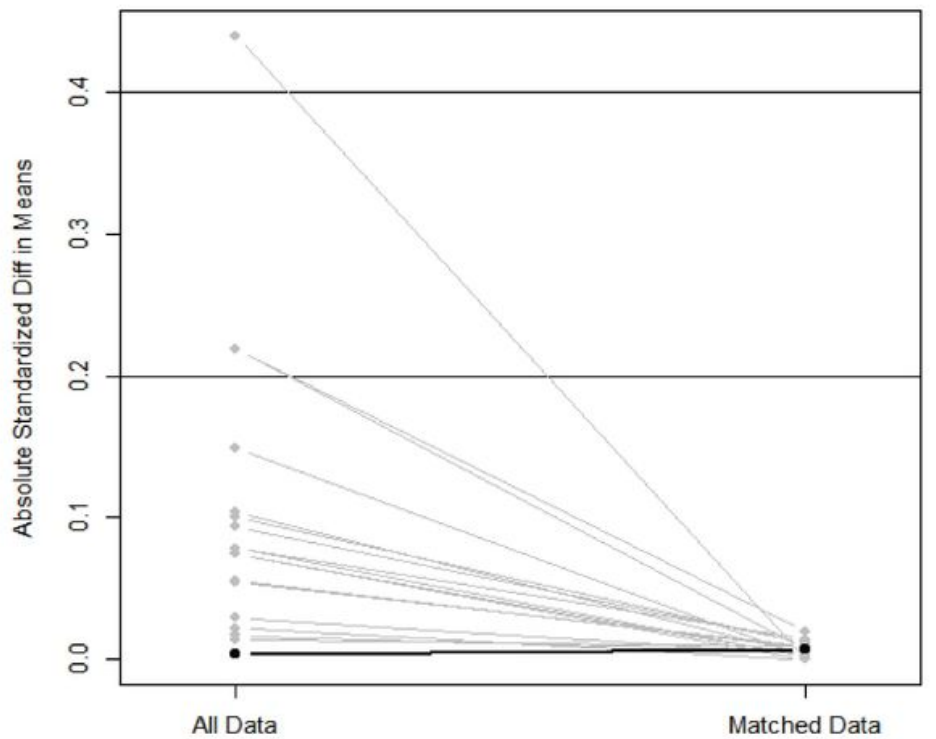

D

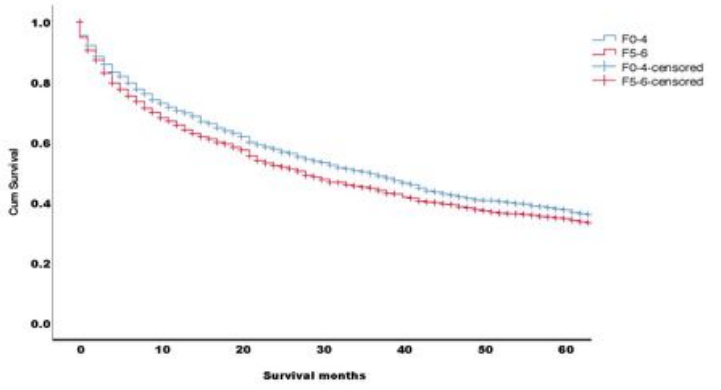

Figure 2 
A

Points
Age
Fibrosis group
AJCC T
AJCC M
Tumor size
Vascular invasion
AFP level
Total Points
1-years Survival Probability
3-years Survival Probability
5-years Survival Probability

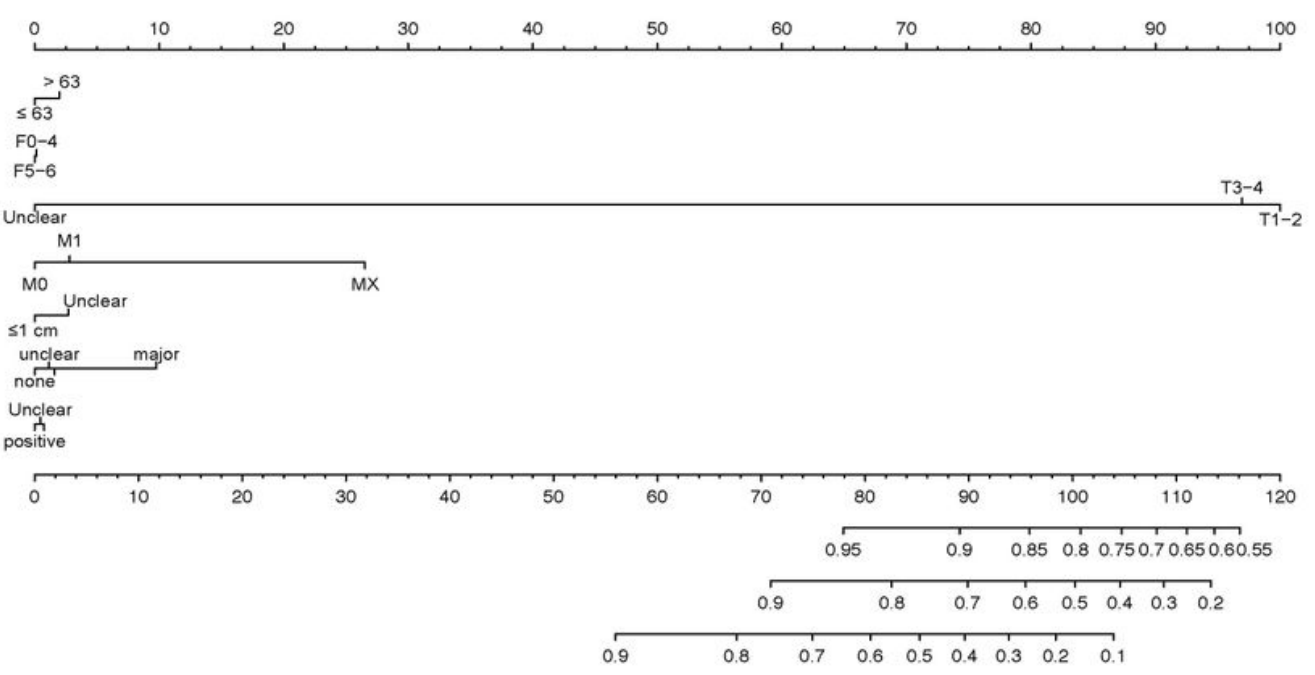

B

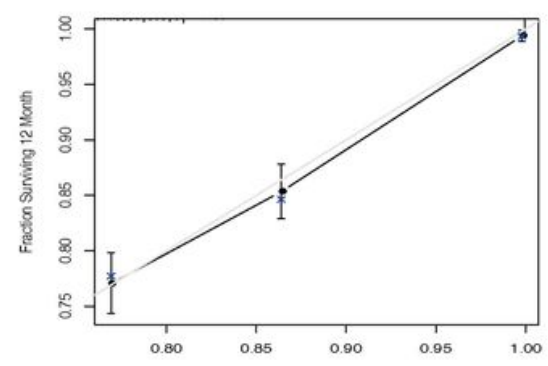

C

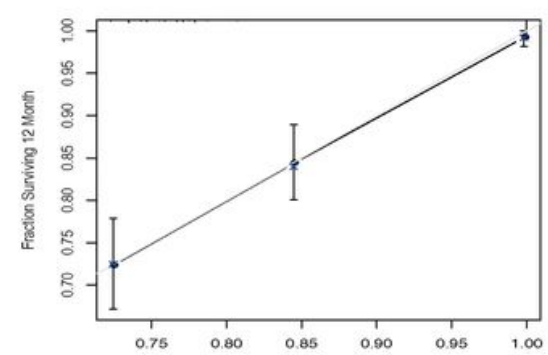

3-year OS in all cohort

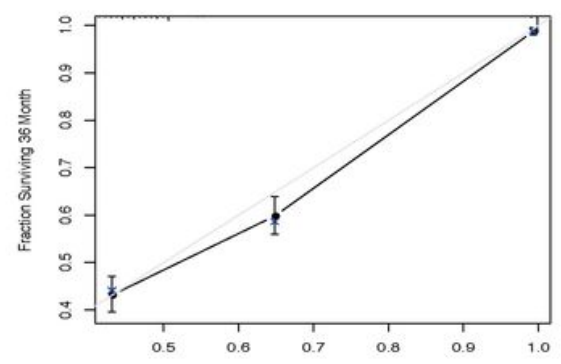

3-year OS in validation cohort

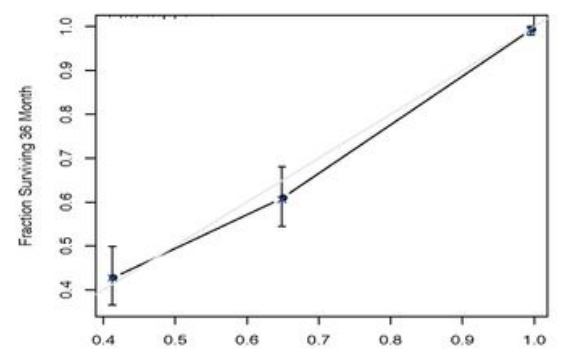

5-year OS in all cohort

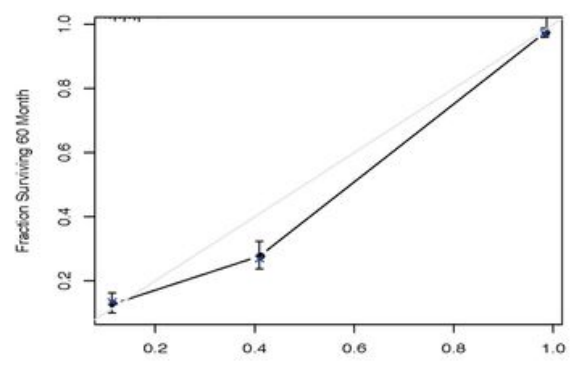

5-year OS in validation cohort

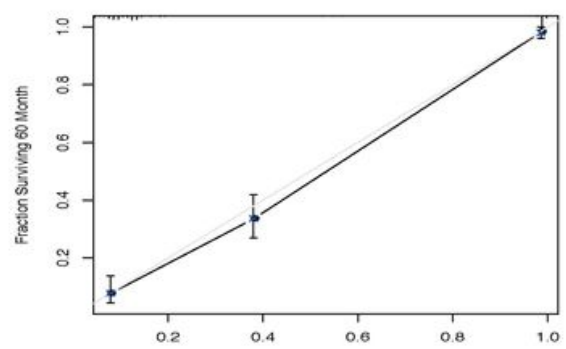

Figure 3 